\title{
Differences in Leaf Cuticle Structure and Efficacy among Eastern Redbud and Mexican Redbud Phenotypes
}

\author{
Jimmy L. Tipton ${ }^{1}$ and Marcia White ${ }^{2}$ \\ Department of Plant Sciences, University of Arizona, Tucson, AZ 85721 \\ 'Additional index words. Cercis canadensis, Cercis canadensis var. mexicana, cuticular transpiration, cuticular wax
}

\begin{abstract}
The objective of this study was to compare the structure and efficacy in terms of retarding cuticular transpiration of leaf cuticles from eastern redbud (Cercis canadensis L.) and dull-leaf and glossy-leaf Mexican redbud [Cercis canadensis var. mexicana (Rose) M. Hopk.]. Leaves of Mexican redbud exhibited several xeromorphic characteristics compared to eastern redbud: a smaller, thicker leaf with thicker cuticles, more cuticular wax, a higher specific leaf mass, and greater hydrated water content on a leaf area basis. Mexican redbuds with a glossy leaf differed from those with a dull leaf only in a thicker adaxial cuticle lacking wax crystallite on the surface. Epicuticular wax crystallite were present on the abaxial surface of all leaves examined. Detached leaves of eastern redbud had a higher water loss rate than those of Mexican redbud only on a dry mass basis, not on a leaf area basis. There was no difference in the rate of water loss by detached leaves of glossy-leaf and dull-leaf Mexican redbuds after 4 hours.
\end{abstract}

Eastern redbud is widely distributed throughout the eastern half of the United States. The tree is variable in leaf morphology and physiology and is responsive to the environment. Eastern redbuds can adapt to $100 \%$ to $47 \%$ sun (Norcini et al., 1991 ), and those from northern populations enter dormancy quicker and have longer chilling requirements than those from southern populations (Donselman and Flint, 1982). A positive correlation between increasing aridity within the native range and xeromorphic characteristics such as increased pubescence, thicker and smaller leaves, and reduced stomatal density has also been reported for eastern redbud (Abrams, 1986; Abrams, 1988; Donselman and Flint, 1982).

Mexican redbud is a variety of eastern redbud native to west Texas and Coahuila, Nuevo León, and San Luis Potosí in Mexico. Like the species, Mexican redbud foliage is extremely variable; the only consistent distinguishing features are coriaceous leaves and pubescent petioles and branchlets (Hopkins, 1942). Whatever other characteristics might be expressed, Mexican redbud leaves will have either a comparatively thin, dull cuticle or a thick, glossy cuticle. Frequently, desirable plants with the glossy cuticle also have undulate leaf margins. This combination has been called the most beautiful foliage of all cultivated redbuds (Raulston, 1990). The glossy leaf phenotype has been reported only in Mexican redbud and the closely related Texas redbud [Cercis canadensis var. texensis (Wats.) Rose], which also grows in relatively dry habitats.

Thick cuticles are a common xeromorphic adaptation thought to retard cuticular transpiration. Leaf cuticles consist primarily of cutin and wax over a layer of cellulose microfibrils (Holloway, 1980). Waxes occur embedded in the cutin matrix and as an epicuticular layer. Although the amount of cutin can vary consid-

Received for publication 18 Mar. 1994. Accepted for publication 29 June 1994. Mention of a trademark or proprietary product does not imply endorsement of the product named nor criticism of similar ones not named. We gratefully acknowledge the assistance of Wayne MacKay, Texas A\&M Research and Extension Center at El Paso, in obtaining plant material and David Bentley, University of Arizona Interdisciplinary Research Laboratory, in SEM procedures. The cost of publishing this paper was defrayed in part by the payment of page charges. Under postal regulations, this paper therefore must be hereby marked advertisement solely to indicate this fact,

'Extension specialist, ornamental horticulture.

${ }^{2}$ Research specialist. erably, particularly among xerophytes (Lyshede, 1980), waxes provide most of the resistance to oxygen and water permeability (Lendzian, 1982; Schönherr, 1976; Tischler and Voigt, 1990).

The glossy cuticle form of Mexican redbud may provide an adaptive advantage that can be exploited in urban landscapes. The objective of this study was to compare the structure and efficacy in terms of retarding cuticular transpiration of leaf cuticles from eastern redbud and dull-leaf and glossy-leaf Mexican redbuds. This study is part of an ongoing effort to domesticate the Mexican redbud (Tipton, 1990, 1992).

\section{Materials and Methods}

Plant material. Greenhouse and landscape plants were used in experiments, but wax content was measured on greenhouse plants only. Greenhouse plants were 1 year old and grown in Tucson, Ariz. This group included eastern redbud as well as dull- and glossy-leaf Mexican redbuds. All plants were grown in a medium of equal parts by volume of peat, sand, vermiculite, and bark in 31 cm-high and 28-cm-top-diameter containers spaced so that shading was minimal. The eastern redbuds were grown from seed collected from native stands in Richardson County, Neb. Greenhouse Mexican redbuds originated as open-pollinated seed from landscape plants. Three dull- and five glossy-leaf Mexican redbuds were growing in a landscape at the Texas A\&M Research and Extension Center in El Paso. All of these plants were 7 years old from seed collected from native stands in Brewster County, Texas.

Scanning electron microscopy (SEM). Two leaves were taken from each of three plants of each type in the greenhouse. Leaves chosen were the second and third fully expanded leaf from a randomly selected branch. Rectangles measuring $5 \times 2.5 \mathrm{~mm}$ were cut from either side of the midvein of each leaf. These samples were fixed overnight in 1\% glutaraldehyde and 4910 formaldehyde in $0.1 \mathrm{M}$ phosphate buffer at $\mathrm{pH}$ 7.4. The samples were postfixed in $1 \%$ osmium tetroxide in $0.1 \mathrm{M}$ phosphate buffer at $\mathrm{pH} 7.4$ for $2 \mathrm{~h}$ then dehydrated in ethanol. The tissue was fractured in liquid $\mathrm{N}$ with a razor blade and critical-point dried using carbon dioxide. Fractured pieces were mounted edgewise on aluminum studs and coated with $\approx 30 \mathrm{~nm}$ of gold by a sputter coater (Hummer 1; Technics, Alexandria, Vs.). The tissue was examined in an ISI DS130 SEM (Topcon Technologies, Pleasanton, Calif.) at $20 \mathrm{kV}$. 
Table 1. Analyses of variance and means for leaf and cuticle thickness for redbud plants growing in a greenhouse and in a landscape.

\begin{tabular}{|c|c|c|c|c|c|c|c|c|c|c|c|c|c|}
\hline \multirow[b]{4}{*}{ Source $^{2}$} & \multicolumn{6}{|c|}{ Greenhouse plants } & \multicolumn{7}{|c|}{ Landscape plants } \\
\hline & \multirow{2}{*}{\multicolumn{2}{|c|}{ Leaf thickness $(\mu \mathrm{m})$}} & \multicolumn{4}{|c|}{ Cuticle thickness $(\mu \mathrm{m})$} & \multirow{2}{*}{\multicolumn{3}{|c|}{$\begin{array}{l}\text { Leaf thickness } \\
(\mathrm{pm})\end{array}$}} & \multicolumn{4}{|c|}{ Cuticle thickness $(\mu \mathrm{m})$} \\
\hline & & & \multicolumn{2}{|c|}{ Abaxial } & \multicolumn{2}{|c|}{ Adaxial } & & & & \multicolumn{2}{|c|}{ Abaxial } & \multicolumn{2}{|c|}{ Adaxial } \\
\hline & $\mathrm{df}$ & MS & $\mathrm{df}$ & MS & $\mathrm{df}$ & MS & & $\mathrm{df}$ & MS & $\mathrm{df}$ & MS & $\mathrm{df}$ & MS \\
\hline Phenotypes & 2 & $67859 * *$ & 2 & $3.69^{*}$ & 2 & $13.8^{* *}$ & & 1 & 18401 & 1 & $5.5^{\mathrm{NS}}$ & 1 & $19.8^{* *}$ \\
\hline MG VS. MD & 1 & $1095^{\mathrm{NS}}$ & 1 & $0.62^{\mathrm{NS}}$ & 1 & $8.4 * *$ & & & & & & & \\
\hline MG + MD VS. E & 1 & $134623 * *$ & 1 & $6.76^{* *}$ & 1 & $19.2^{* * *}$ & & & & & & & \\
\hline Plants (phenotype) & 6 & 12332 & ss 6 & $0.91^{\mathrm{NS}}$ & 6 & 0.4 & Ns & 64 & $10322^{\mathrm{Ns}}$ & & $0.5^{\mathrm{NS}}$ & 4 & $0.9^{\mathrm{Ns}}$ \\
\hline Leaves (plant) & 9 & $4872^{\mathrm{NS}}$ & & 0.60 & 9 & $1.3^{\mathrm{Ns}}$ & & 6 & $5507 * *$ & 6 & $2.6^{*}$ & 6 & $2.4^{* *}$ \\
\hline Segments (leaf) & 36 & $2581^{* *}$ & 36 & $0.28 * *$ & 36 & 0.7 & ns & 24 & $194 * *$ & 24 & $0.4 ”$ & 24 & $0.8^{* *}$ \\
\hline Location (segment) & 108 & 73 & 216 & 0.06 & 216 & 0.1 & & 72 & 82 & 144 & 0.1 & 144 & 0.2 \\
\hline \multicolumn{14}{|l|}{ Mean \pm SE } \\
\hline MG & \multicolumn{2}{|c|}{$222 \pm 12$} & \multicolumn{2}{|c|}{$2.1 \pm 0.1$} & \multicolumn{2}{|c|}{$3.0 \pm 0.1$} & \multicolumn{3}{|c|}{$287 \pm 6$} & \multicolumn{2}{|c|}{$2.7 \pm 0.1$} & \multicolumn{2}{|c|}{$4.0 \pm 0.1$} \\
\hline MD & \multicolumn{2}{|c|}{$211 \pm 4$} & \multicolumn{2}{|c|}{$1.9 \pm 0.1$} & \multicolumn{2}{|c|}{$2.2 \pm 01$} & & \multicolumn{2}{|c|}{$261 \pm 4$} & \multicolumn{2}{|c|}{$2.4 \pm 0.1$} & \multicolumn{2}{|c|}{$3.4 \pm 0.1$} \\
\hline E & \multicolumn{2}{|c|}{$111 \pm 2$} & \multicolumn{2}{|c|}{$1.4 \pm 0.1$} & \multicolumn{2}{|c|}{$1.6 \pm 0.1$} & & & & & & & \\
\hline
\end{tabular}

$\overline{\mathrm{T}} \mathrm{MG}=$ Glossy-leaf Mexican, $\mathrm{MD}=$ Dull-leaf Mexican, $\mathrm{E}=$ Eastern.

“**** *Nonsignificant or significant at $P=0.05$ or 0.01 , respectively.

Entire leaf segments were microphotographed at 150 to $250 \times$ magnification. Three segments from each leaf were examined and photographed. Leaf thickness was measured at three locations on each microphotograph. Microphotograph negatives were placed in a darkroom enlarger and thickness of the adaxial and abaxial cuticle measured on the enlarged images. Cuticle thickness was measured at the midpoint of a cell at five locations on each negative. As a check on this technique, adaxial cuticles were also photographed at 5000× magnification and thickness measured directly from the microphotograph. Fresh samples were examined to ensure that tissue fixation and preparation did not significantly influence cuticular wax. These samples, from the same leaves as the fixed tissue, were sputter coated and viewed as described above. Leaves from the landscape plants were treated in the same manner.

Cuticular transpiration. Cuticular transpiration was measured gravimetrically. Four leaves each were taken from three plants of each type in the greenhouse. Leaves chosen were the second and third fully expanded leaf from randomly selected branches. Rafts were constructed of window screen glued to a styrofoam ring. Leaves were placed on the rafts with their petioles sticking through the screen. The rafts were placed on water in a resealable plastic container with the petioles submerged. The containers were sealed and placed in a controlled environment at 20C overnight. The hydrated leaves were then removed from the containers and weighed at hourly intervals as they dried in the same controlled environment. Leaf area was measured using a leaf area meter and the leaves were dried to a constant mass at 60C. Leaves from landscape plants were sealed in polyethylene bags, transported to Tucson in a cooler, then treated in the same manner, except leaf area was not determined.

Wax content. Wax content was measured on greenhouse plants only. Twenty leaves each were taken from three plants of each type. Leaves chosen were the second through sixth fully expanded leaf from a randomly selected branch. Six 1.6-cm-diameter disks were punched from each leaf using a no. 6 cork borer, three from each side of the midvein. The 120 disks per plant were combined in a single beaker and wax extracted by a modification of previously reported procedures (Ebercon et al., 1977; Eigenbrode et al., 1991). The samples were immersed in $30 \mathrm{ml}$ dichloromethane for $30 \mathrm{sec}$ followed by three immersions in $30 \mathrm{ml}$ chloroform, each for 30 sec. The solvents were decanted through a Whatman \#1 filter into a clean beaker of known mass. Beakers and filter paper were rinsed with chloroform and the rinseate added to the solvents. The

Table 2. Analysis of variance and means for leaf area, specific leaf mass, and water content of hydrated leaves for redbud plants growing in a greenhouse.

\begin{tabular}{|c|c|c|c|c|c|c|c|c|}
\hline \multirow[b]{3}{*}{ Source $^{2}$} & \multirow{2}{*}{\multicolumn{2}{|c|}{$\begin{array}{l}\text { Leaf area } \\
\left(\mathrm{cm}^{2}\right)\end{array}$}} & \multirow{2}{*}{\multicolumn{2}{|c|}{$\begin{array}{c}\text { Specific leaf } \\
\text { mass } \\
\left(\mathrm{mg} \cdot \mathrm{cm}^{-2}\right)\end{array}$}} & \multicolumn{4}{|c|}{ Water content } \\
\hline & & & & & \multicolumn{2}{|c|}{$\begin{array}{c}\text { Leaf area } \\
\text { basis } \\
\left(\mathrm{mg} \cdot \mathrm{cm}^{-2}\right)\end{array}$} & \multicolumn{2}{|c|}{$\begin{array}{c}\text { Dry mass } \\
\text { basis } \\
\left(\mathrm{g} \cdot \mathrm{g}^{1}\right)\end{array}$} \\
\hline & $\mathrm{df}$ & MS & $\overline{d f}$ & MS & $\mathrm{df}$ & MS & $\mathrm{df}$ & MS \\
\hline Phenotypes & 2 & $28043 * *$ & 2 & $63.5^{* *}$ & 2 & $194.3^{* *}$ & 2 & $0.03^{\mathrm{NS}}$ \\
\hline MG vs. MD & 1 & $1128^{\mathrm{NS}}$ & 1 & $3.1^{\mathrm{NS}}$ & 1 & $5.8^{\mathrm{Ns}}$ & 1 & $0.01^{\mathrm{NS}}$ \\
\hline $\mathrm{MG}+\mathrm{MD}$ vs. $\mathrm{E}$ & 1 & $54957 * *$ & 1 & $123.8^{* *}$ & 1 & $382.7^{* *}$ & 1 & $0.06^{\mathrm{NS}}$ \\
\hline Plants (phenotype) & 6 & 437 & 9 & $3.3^{* *}$ & 6 & $6.0^{*}$ & 6 & $0.02^{\mathrm{NS}}$ \\
\hline Leaves (plant) & 27 & 133 & 3 & $0.6 "$ & 27 & 1.7 & 27 & 0.03 \\
\hline \multicolumn{9}{|l|}{ Means \pm SE } \\
\hline MG & \multicolumn{2}{|c|}{$48 \pm 13$} & \multicolumn{2}{|c|}{$9.1 \pm 0.2$} & \multicolumn{2}{|c|}{$19.9 \pm 1.4$} & \multicolumn{2}{|c|}{$2.3 \pm 0.2$} \\
\hline MD & \multicolumn{2}{|c|}{$34 \pm 7$} & \multicolumn{2}{|c|}{$8.5 \pm 0.3$} & \multicolumn{2}{|c|}{$18.9 \pm 2.0$} & \multicolumn{2}{|c|}{$2.3 \pm 0.1$} \\
\hline $\mathrm{E}$ & \multicolumn{2}{|c|}{$124 \pm 19$} & \multicolumn{2}{|c|}{$5.4 \pm 0.3$} & \multicolumn{2}{|c|}{$12.5 \pm 1.3$} & \multicolumn{2}{|c|}{$2.4 \pm 0.2$} \\
\hline
\end{tabular}

${ }^{\mathrm{M} G}=$ glossy-leaf Mexican, $\mathrm{MD}=$ dull-leaf Mexican, $\mathrm{E}=$ eastern.

Ns,*, **Nonsignificant or significant at $P=0.05$ or 0.01 , respectively. 

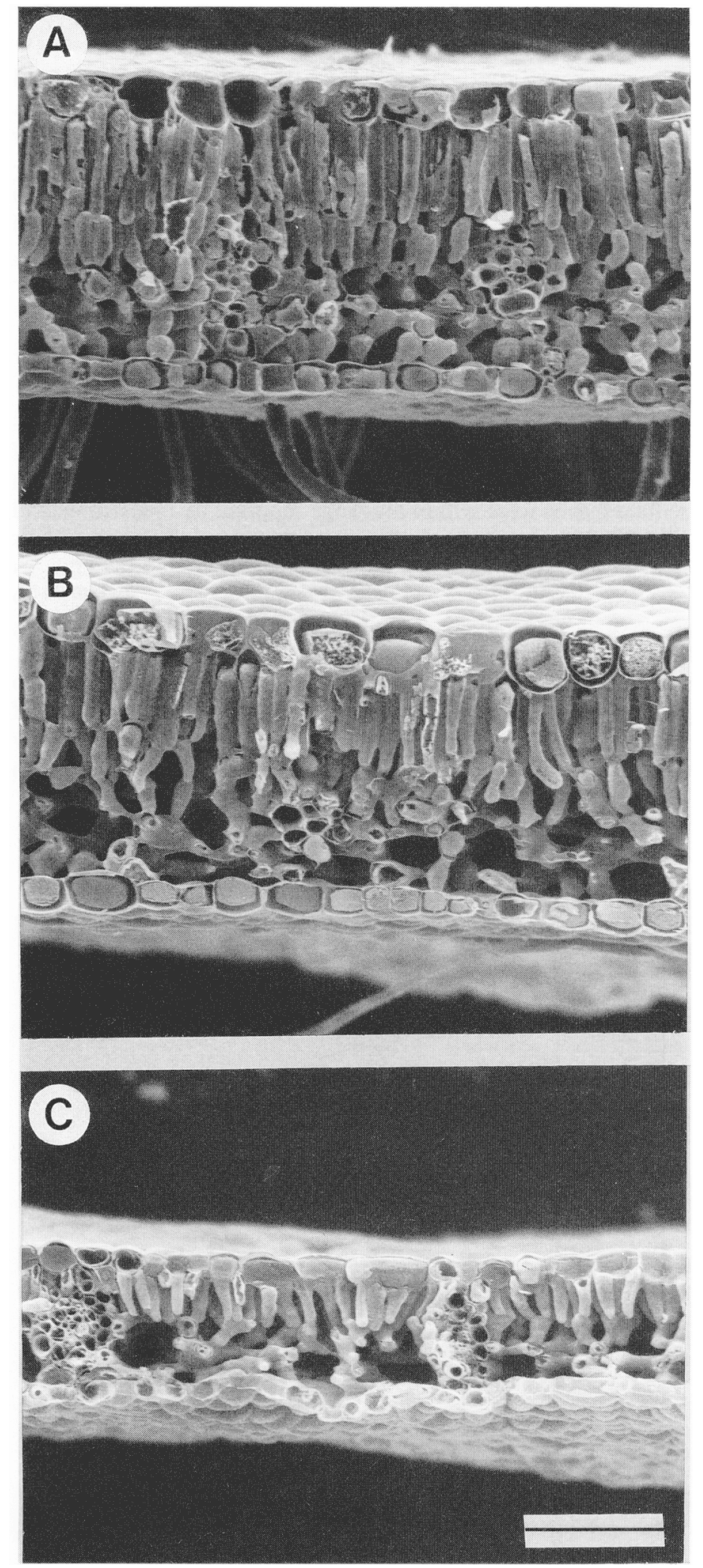

Fig. 1. Cross sections of leaves from glossy-leaf Mexican (A), dull-leaf Mexican (B), and eastern redbuds (C). Scale bar $=100 \mu \mathrm{m}$.

solvents were evaporated under a fume hood at room temperature until beaker mass was constant and wax residue mass determined. The leaf disks were dried to a constant mass at 60C. The entire experiment was repeated.

Statistical analysis. Analyses of variance of the data was
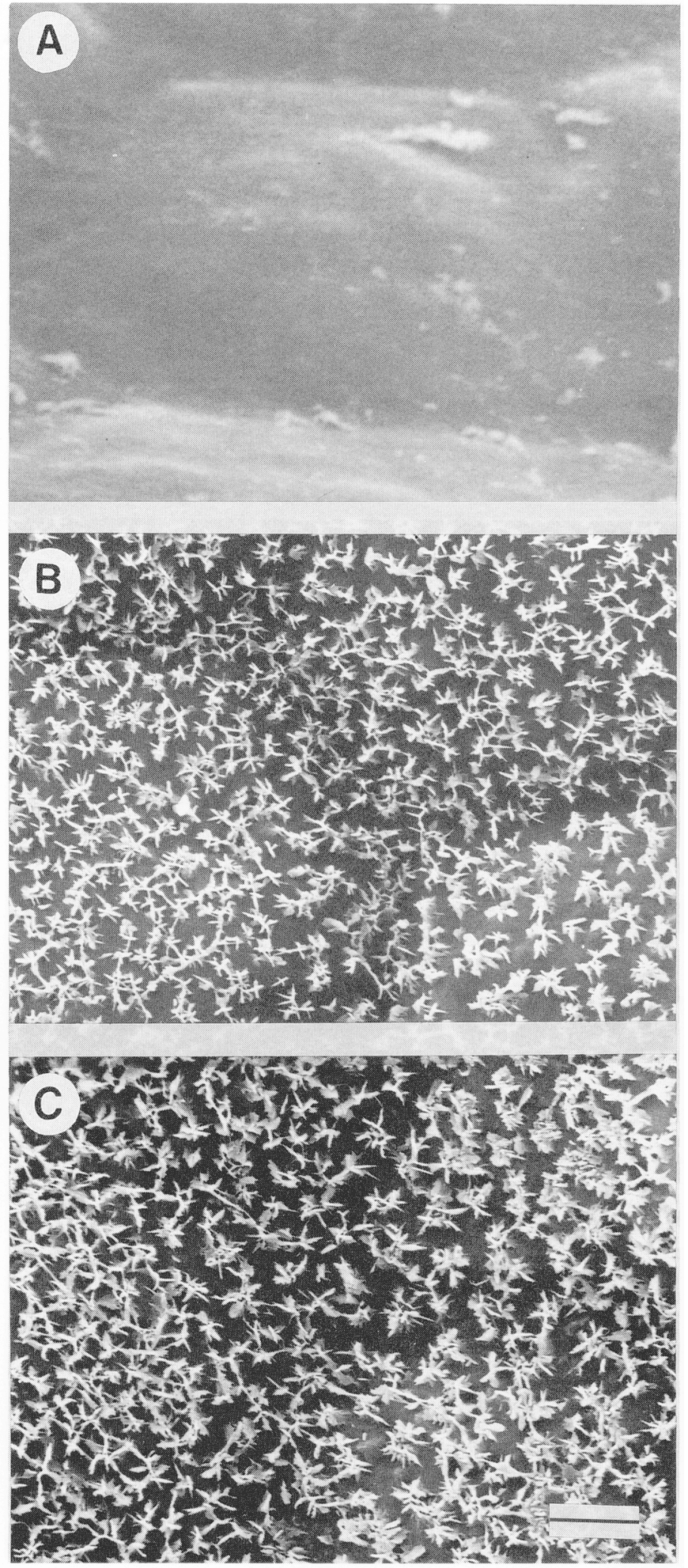

Fig.2.Adaxial surface of leaves from glossy-leaf Mexican (A), dull-leaf Mexican (B), and eastern redbuds (C). Scale bar $=5 \mu \mathrm{m}$.

conducted in a nested design for all measurements except water loss rate. Leaves were nested within plants, which were nested within phenotypes. Nonsignificant nested sources of variation were pooled to test the effect of phenotypes. When appropriate, phenotype means were compared by orthogonal contrasts to test 


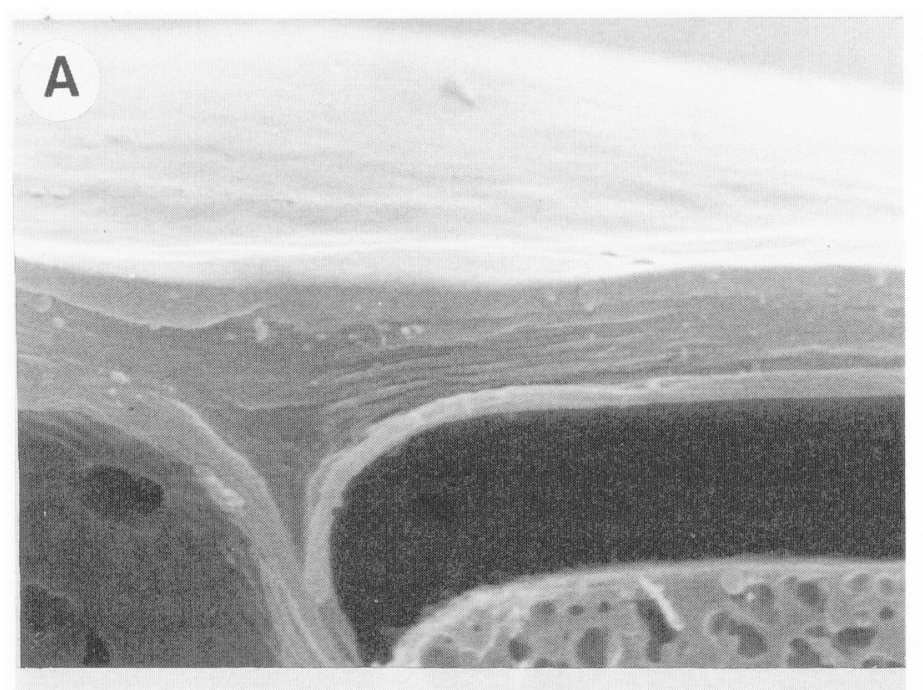

\section{B}
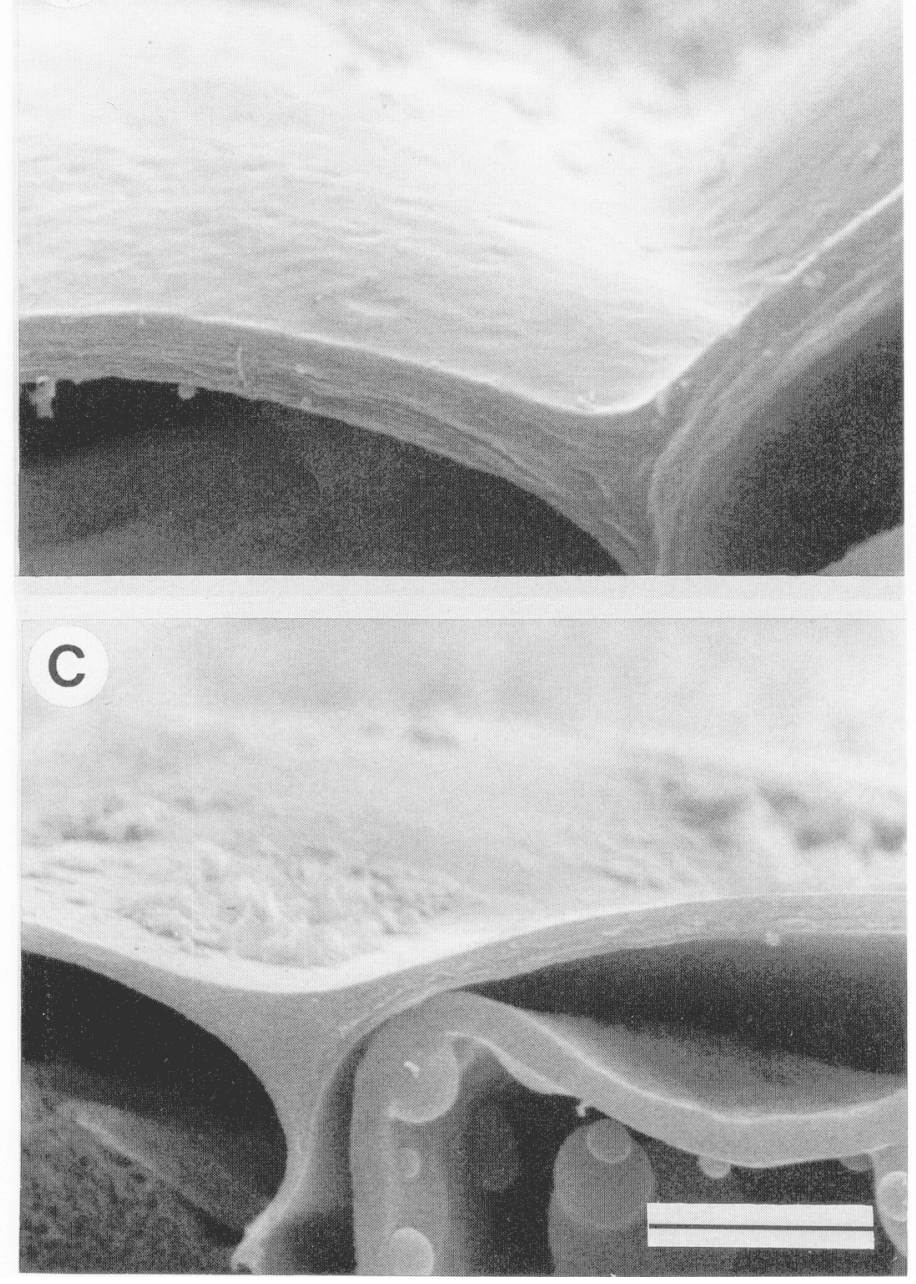

Fig.3.Crosssectionofadaxial leaf cuticle from glossy-leaf Mexican (A), dull-leaf Mexican (B), and eastern redbuds (C). Scale bar $=5 \mathrm{pm}$.

two hypotheses: 1) there was no difference between eastern and Mexican redbuds and 2) there was no difference between the dulland glossy-leaf Mexican redbuds.

Leaf water loss rate on a dry mass and leaf area basis was analyzed via multiple linear regression with indicator variables for plant type (Neter et al., 1983). The full model was

$\mathrm{Y}=\mathrm{B}_{0}+B_{1} X+\mathrm{B}_{2}$ Dull $+\mathrm{B}_{3}$ East $+\mathrm{B}_{4}$ Du1l $+B_{5} X$ East

where $\mathrm{Y}$ was $\log$ (water loss rate), $X$ was $\log$ (time), and Dull and East were 0 or 1 as appropriate for the corresponding data. Testing of three hypotheses determined whether the regression for dull-leaf Mexican redbud was equal to that for glossy-leaf Mexican redbud, whether the regression for eastern redbud was equal to that for glossy-leaf Mexican redbud, and whether the regression for dull-leaf Mexican redbud was equal to that for eastern redbud, respectively: 1) $\left.B_{2}=B_{4}=0,2\right) \quad B_{3}=B_{5}=0$, and 3) $B_{2}=B_{3}=B_{4}-$ $\mathrm{B}_{5}=0$. Reduced regression equations are reported.

\section{Results and Discussion}

SEM. Mexican redbud exhibited typical xeromorphic adaptations. The leaves were smaller but nearly twice as thick as those of eastern redbud (Tables 1 and 2). Area and thickness of the eastern redbud leaves were within the range reported by Donselman and Flint (1982). But these leaves were somewhat larger and thinner than those of Abrams (1986; 1988). In fact, leaf area and thickness of Mexican redbuds growing in a greenhouse were comparable to those of eastern redbuds growing on the Kansas prairie (Abrams, 1986).

Leaf cells were more densely packed in Mexican compared to eastern redbud and there was a poorly formed second row of palisade parenchyma (Fig. 1). As a result, specific leaf mass (dry mass per unit leaf area) was significantly higher for Mexican
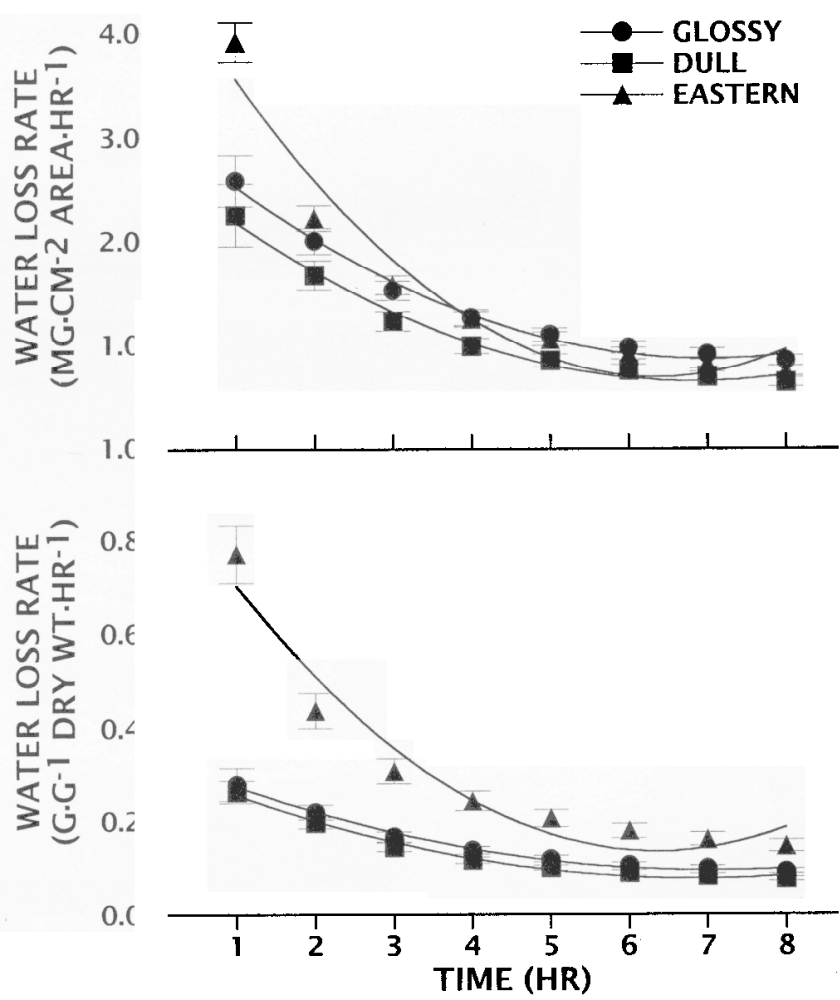

Fig. 4. Water loss on a leaf area (A) and dry weight basis (B) by detached leaves of glossy-leaf Mexican, dull-leaf Mexican, and eastern redbuds grown in a greenhouse.Verticalbarsrepresent \pm 1 SE.Reducedregressionequationsfor A are glossy-leaf Mexican redbud-Y $=2.53 \mathrm{~T}^{-0.54}$; dull-leaf Mexican redbud-Y $=$ $2.05 \mathrm{~T}^{-0.57} \cdot$; andeasternredbud- $\mathrm{Y}=3.78 \mathrm{~T}^{-0.81}$, where $\mathrm{Y}$ is water loss rate and $\mathrm{T}$ is time. Reduced regression equations for B are: glossy-leaf Mexican redbud$\mathrm{Y}=0.28 \mathrm{~T}-0.54$, dull-leafMexicanredbud $-\mathrm{Y}=0.24 \mathrm{~T}-0.57$; andeasternredbud$\mathrm{Y}=0.72 \mathrm{~T}^{-0.81}$.Multiplecorrelationfor the full model, after removing pure error sum of squares, was 0.9823 for $\mathbf{A}$ and 0.9873 for $\mathbf{B}$. 
Table 3. Comparison of regression equations for water loss rate on time by detached leaves from redbud plants growing in a greenhouse and in a landscape.

\begin{tabular}{|c|c|c|c|c|c|c|}
\hline \multirow{3}{*}{$\begin{array}{l}\text { Null hypothesis to } \\
\text { compare regression } \\
\text { equations for redbud } \\
\text { phenotypes }^{2} \text {. }\end{array}$} & \multicolumn{4}{|c|}{ Greenhouse plants } & \multirow{2}{*}{\multicolumn{2}{|c|}{$\begin{array}{c}\text { Landscape plants } \\
\text { Water loss rate } \\
(\mathrm{g} / \mathrm{g} \text { dry wt per } \mathrm{h})\end{array}$}} \\
\hline & \multicolumn{2}{|c|}{$\begin{array}{c}\text { Water loss rate } \\
\left(\mathrm{mg} / \mathrm{cm}^{2} \text { leaf area per } \mathrm{h}\right)\end{array}$} & \multicolumn{2}{|c|}{$\begin{array}{l}\text { Water loss rate } \\
(\mathrm{g} / \mathrm{g} \text { dry wt per } \mathrm{h})\end{array}$} & & \\
\hline & $1-8 \mathrm{~h}$ & $4-8 \mathrm{~h}$ & $1-8 \mathrm{~h}$ & $4-8 \mathrm{~h}$ & $2-8 \mathrm{~h}$ & $4-8 \mathrm{~h}$ \\
\hline $\mathrm{B}_{2}=\mathrm{B}_{4}=0 \quad\left(\mathrm{MD}=\mathrm{MG}^{y}\right)$ & & & NS & NS & & NS \\
\hline $\mathrm{B}_{3}=\mathrm{B}_{5}=0 \quad(\mathrm{E}=\mathrm{MG})$ & $* *$ & NS & $* *$ & $* *$ & & \\
\hline $\mathrm{B}_{2}-\mathrm{B}_{4}=\mathrm{B}_{3}-\mathrm{B}_{5}=0$ & $* *$ & $* *$ & $* *$ & $* *$ & & \\
\hline
\end{tabular}

${ }^{2}$ Full model is $\mathrm{Y}=\mathrm{B}_{0}+\mathrm{B}_{1} \mathrm{X}+\mathrm{B}_{2} \mathrm{Du} 11+\mathrm{B}_{3}$ Eastern $+\mathrm{B}_{4} \mathrm{XDull}+\mathrm{B}_{5} \mathrm{XEastern}$, where $\mathrm{Y}=\log ($ water $\operatorname{loss}$ rate $)$ and $\mathrm{X}=\log ($ time $)$.

${ }^{\mathrm{y}} \mathrm{MG}=$ Glossy-leaf Mexican redbud, $\mathrm{MD}=$ dull-leaf Mexican redbud, $\mathrm{E}=$ eastern redbud.

Ns.** Nonsignificant or significant at $\boldsymbol{P}=0.01$, respectively,

redbud over eastern redbud (Table 3). Specific leaf mass of the eastern redbud was much less than the 8.8 to $12.0 \mathrm{mg} \cdot \mathrm{cm}^{-2}$ reported by Norcini et al. (1991), but greater than the 2.7 to $3.6 \mathrm{mg} \cdot \mathrm{cm}^{-2}$ in greenhouse plants reported by Abrams (1988). The specific leaf mass of Mexican redbuds growing in a greenhouse was only slightly greater than that of eastern redbuds growing in the Kansas prairie (Abrams, 1986).

Abaxial and adaxial cuticles were $>35 \%$ thicker in Mexican redbud regardless of surface phenotype. The adaxial surface in Eastern and dull-leaf Mexican redbud leaves was covered with epicuticular wax crystallite lacking in glossy-leaf Mexican redbuds (Fig. 2). Epicuticular wax crystallite were present on the abaxial leaf surface of all three plants. The adaxial cuticle of glossy-leaf Mexican redbud was thicker than that of dull-leaf plants, but there was no significant difference in the leaf or abaxial cuticle thickness between these phenotypes (Table 1, Fig. 3). This relationship was consistent among greenhouse and landscape plants.

Cuticular transpiration. Water content of hydrated leaves on a dry mass basis was very similar for all three plant types in the greenhouse (Table 2). On a leaf area basis, water content of Mexican redbud was $50 \%$ higher. Water loss rate declined in a logarithmic fashion from 1 to $8 \mathrm{~h}$ (Fig. 4). Previous work with this species and a cursory examination suggested that stomata should be closed by the second hour, but there was a substantial decline in water loss rate from hour 2 to 3 , at least for eastern redbud. A similar prolonged delay in stomatal closure has been observed in balsam fir (DeLucia and Berlyn, 1984). To ensure that stomatal transpiration was not influencing conclusions, we conducted regression analysis twice, once over the span of 1 to $8 \mathrm{~h}$ and again over the span of 4 to $8 \mathrm{~h}$ (Table 3). Lines drawn in Fig. 4 represent

Table 4. Analysis of variance and means for cuticular wax content from redbud plants growing in a greenhouse.

\begin{tabular}{|c|c|c|}
\hline \multirow[b]{2}{*}{ Source ${ }^{2}$} & \multicolumn{2}{|c|}{$\begin{array}{c}\text { Cuticular wax content } \\
\left(\mu \mathrm{g} \cdot \mathrm{cm}^{-2}\right)\end{array}$} \\
\hline & $\mathrm{df}$ & MS \\
\hline Phenotypes & 2 & $22.7^{\mathrm{NS}}$ \\
\hline MG vs MD & 1 & $43.0 *$ \\
\hline $\mathrm{MG}+\mathrm{MD}$ vs. $\mathrm{E}$ & 1 & $2.3^{\mathrm{NS}}$ \\
\hline Plants (phenotype) & 6 & $10.1^{\mathrm{NS}}$ \\
\hline Error & 9 & 4.1 \\
\hline \multicolumn{3}{|l|}{ Mean \pm SE } \\
\hline MG & & $18.6 \pm 0.7$ \\
\hline MD & & $19.4 \pm 0.9$ \\
\hline $\mathrm{E}$ & & $15.7 \pm 1.4$ \\
\hline
\end{tabular}

the first analysis only. On a leaf area basis, dull-leaf Mexican redbud hand a significantly lower rate of water loss over the duration than either glossy-leaf Mexican or eastern redbud (Fig. 4A, Table 3 ); however, there was no significant difference in water loss rates between the latter plants from 4 to $8 \mathrm{~h}$. On a dry mass basis, eastern redbud had a significantly higher water loss rate throughout (Fig. $4 \mathrm{~B}$, Table 3). Leaves of eastern redbud lost $32 \%$ of their water during the first hour compared to only $12 \%$ and $14 \%$ for the dulland glossy-leaf Mexican redbuds, respectively. After 8 hours, leaves of eastern redbud had lost almost half of their water (49\%) vs. $36 \%$ and $26 \%$ for the dull- and glossy-leaf Mexican redbuds, respectively.

Leaves of the landscape plants lost water at a greater rate during the second hour than during the first (Fig. 5), so we excluded data from the first hour in calculating regressions. Unlike results from the greenhouse plants, glossy-leaf Mexican redbud leaves had a significantly lower initial water loss rate than did those from dullleaf Mexican redbuds (Table 3). However, there was no difference between plants after $4 \mathrm{~h}$. Leaves from landscape plants also had higher water loss rates than those from greenhouse plants. As a result, leaves from dull- and glossy-leaf Mexican redbuds in the landscape had lost $85 \%$ and $79 \%$, respectively, of their water after $8 \mathrm{~h}$. The higher water loss rates for leaves from landscape plants may be attributable to irreversible changes that occurred in transport from El Paso to Tucson. Hydrated leaves from landscape plants contained only $1.7 \mathrm{~g} \cdot \mathrm{g}^{-1}$ dry mass of water compared to 2.3 $\mathrm{g} \cdot \mathrm{g}^{-1}$ for leaves from greenhouse plants.

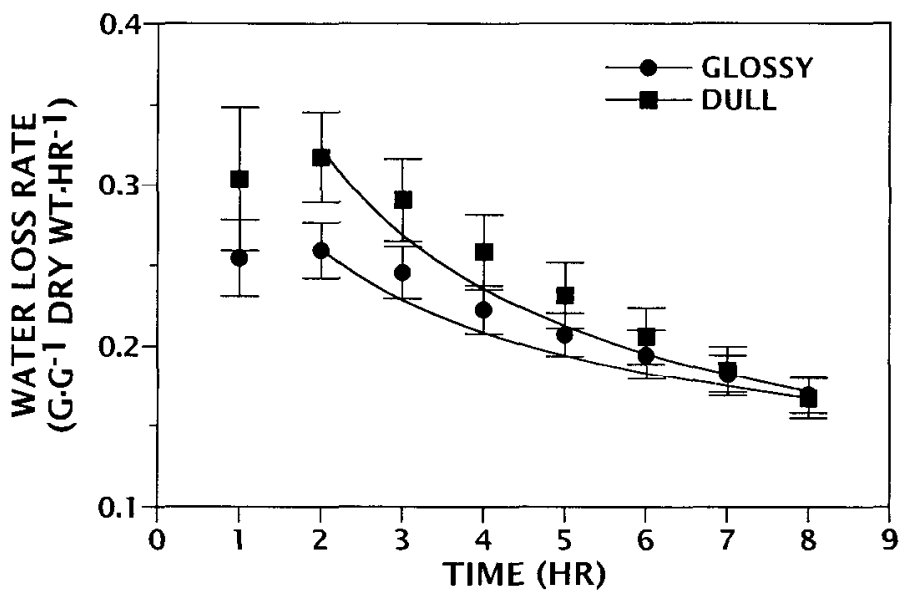

Fig, 5. Water loss on a dry weight basis by detached leaves of glossy-leaf and dullleaf Mexican redbuds grown in a landscape, Vertical bars represent \pm 1 SE. Reduced regression equations are glossy-leaf Mexican redbud-Y $=0.32 \mathrm{~T}^{-0.32}$ and dull-leaf Mexican redbud-Y $=0.45 \mathrm{~T}^{-0.46}$, where $\mathrm{Y}$ is water loss rate and $\mathrm{T}$ is time. Multiple correlation for the full model, after removing pure error sum of squares, was 0.9093 . 
These data suggest that Mexican redbud has not adapted to drought by reducing water lost through cuticular transpiration, which would have resulted in significant differences in water loss rate on a leaf area basis. The differences observed in water loss rate on a dry mass basis reflect the benefits of smaller leaves with a higher specific mass. Mexican redbud avoids dehydration by reducing surface area while maintaining biomass. This results in greater hydration per unit biomass even though water loss per unit surface area is not restricted more than in eastern redbud.

Wax content. Leaves of Mexican redbud had, on average, $20 \%$ more wax per square centimeter than eastern redbud (Table 4). There was no difference in the quantity of wax between the Mexican redbud phenotypes. Crystallite wax may be lacking in the glossy leaves and may account for such a small portion of the total dull-leaf wax that this deficiency could not be detected by our procedure. Alternatively, crystallite wax maybe present in another form in glossy leaves. Regardless, these results suggest that the greater cuticle thickness of glossy leaves can be attributed more to cutin than wax. As previously noted, cutin provides less resistance to oxygen and water permeability than wax so this interpretation is consistent with our results in water loss rates.

Leaves of Mexican redbud exhibit several xeromorphic characteristics compared to eastern redbud: a smaller, thicker leaf with thicker cuticles, more cuticular wax, a higher specific leaf mass, and greater hydrated water content on a leaf area basis. These characteristics contribute to the water conserving capability of Mexican redbud as demonstrated by the lower water loss rate observed on a dry mass basis, and to its survival in arid and semiarid habitats. Whether they will also lead to water conservation in urban landscapes remains unproven.

The glossy-leaf phenotype differs from dull-leaf Mexican redbud only in a thicker adaxial cuticle lacking wax crystallite on the surface. Since the differences occur only on the adaxial surface, they cannot provide a plausible cause for observed differences in water loss rate. While it is possible that the thick, glossy cuticle has no adaptive advantage, this seems unlikely since it occurs only on plants growing in arid habitats. We are investigating whether this characteristic might affect water relations by restricting light transmission and therefore heat accumulation.

\section{Literature Cited}

Abrams, M.D. 1986. Physiological plasticity in water relations and leaf structure of understory versus open-grown Cercis canadensis in northeastern Kansas. Can. J. For. Res. 16:1170-1174.

Abrams, M.D. 1988. Genetic variation in leaf morphology and plant and tissue water relations during drought in Cercis canadensis L. For. Sci. 34:200-207.

DeLucia, E.H. and G.P. Berlyn. 1984. The effect of increasing elevation on leaf cuticle thickness and cuticular transpiration in balsam fir. Can. J. Bet. 62:2423-2431.

Donselman, H.M. and H.L. Flint. 1982. Gynecology of eastern redbud (Cercis canadensis). Ecology 63:962-971.

Ebercon, A., A. Blum, and W .R. Jordon. 1977. A rapid colonmetric method for epicuticular wax content of sorghum leaves. Crop Sci. $17: 179-180$

Eigenbrode, S. K.A. Stoner, A.M. Shelton, and W.C. Kain. 1991. Characteristics of glossy leaf waxes associated with resistance to diamondback moth (Lepidoptera: Plutellidae) in Brassica oleracea. J. Econ. Entomol. 84:1609-1618.

Holloway, P.J. 1980. Structure and histochemistry of plant cuticular membranes: An overview, p. 1-32. In: D.F. Cutler, K.L. Alvin, and C.E. Price (eds.). The plant cuticle. Academic Press, London.

Hopkins, M. 1942. Cercis in North America. Rhodora 44:193-211.

Lendzian, K.J. 1982. Gas permeability of plant cuticles. Planta 155:310315.

Lyshede, O.B. 1980. Structure of the outer epidermal wall in xerophytes, p. 87-98. In: D.F. Cutler, K.L. Alvin, and C.E. Price (eds.). The plant cuticle. Academic Press, London.

Neter, J., W. Wasserman, and M.H. Kutner. 1983. Applied linear regression models. Irwin, Homewood, Ill.

Norcini, J.G., G.W. Knox, and P.C. Andersen. 1991. Leaf gas exchange of eastern redbud (Cercis canadensis L.) grown under sun and shade. J. Environ. Hort. 9:215-218.

Raulston, J.C. 1990. Redbud. Amer. Nurseryman 171(5):39-51.

Schönherr, J. 1976. Water permeability of isolated cuticular membranes: The effect of cuticular waxes on diffusion of water. Planta 131:159-164.

Tipton, J.L. 1990. Vegetative propagation of Mexican redbud, larchleaf goldenweed, littleleaf ash, and evergreen sumac. HortScience 25:196-198.

Tipton, J.L. 1992. Requirements for seed germination of Mexican redbud, evergreen sumac, and mealy sage. HortScience 27:313-316.

Tischler, C.R. and P. W. Voigt. 1990. Variability in leaf characteristics and water loss in the weeping lovegrass complex. Crop Sci. 30:111-117. 